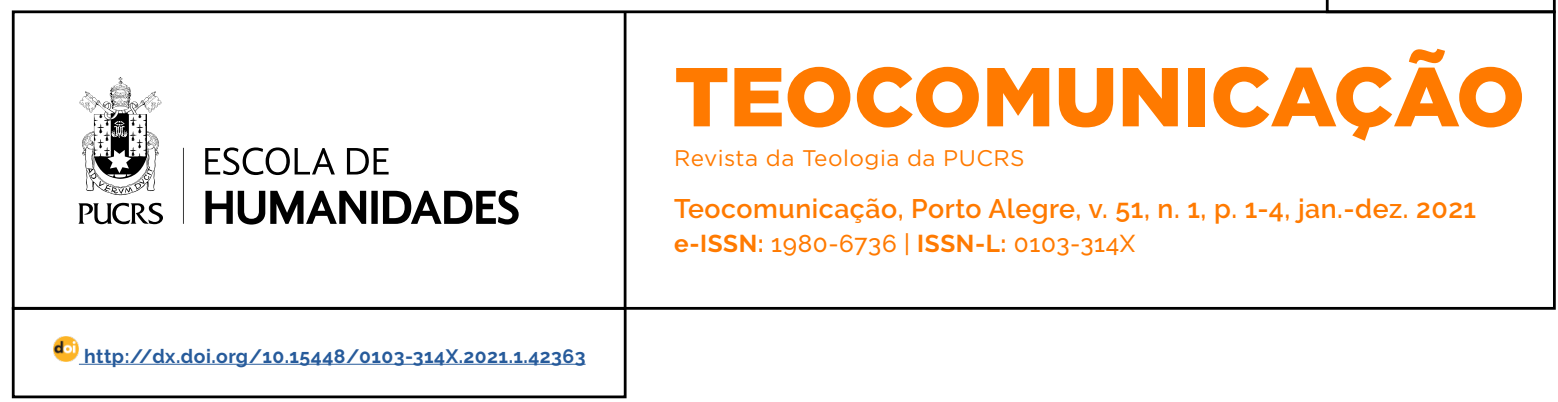

SEÇÃO: LITURGIA

\title{
Liturgia e pandemia
}

\author{
Liturgy and pandemic \\ Liturgia e pandemia
}

\section{Rafael Martins \\ Fernandes ${ }^{1}$}

orcid.org/0000-0003-2416-4862

padrerafaelfernandes@gmail.com

\section{Carlos Gustavo Haas ${ }^{1}$}

orcid.org/0000-0002-6815-5813 gustavohaas251@hotmail.com

Recebido em: 02/12/2021 Aprovado em: 02/12/2021. Publicado em: 30/12/2021.

\section{(c) (i)}

Artigo está licenciado sob forma de uma licença Creative Commons Atribuição 4.0 Internacional.
Resumo: Este editorial reflete sobre a vivência litúrgica das comunidades eclesiais dentro do contexto de pandemia de COVID-19 que abalou o mundo. A perspectiva que ilumina as reflexões é a de uma visão integral e dinâmica da fé cristã, que une culto e vida. São levados em conta os estudos contidos no Dossiê de Liturgia desta edição da Teocomunicação: a) o artigo de Arnaldo Temochko sobre a Liturgia das Horas como possibilidade de oração para os lares: b) o artigo de Rudy Albino da Assunção sobre a Teologia da Liturgia de Bento XVI; c) o artigo de João José Bezerra que versa sobre a Liturgia como ciência teológica e sua relação com as demais ciências; e d) o artigo de Michelle Girardi Lorenzetti que trata dos processos formativos litúrgico-musicais na Arquidiocese de Porto Alegre. Ao final, reafirma-se a necessidade de uma maior aproximação das diferentes realidades presentes na pandemia com a vivência litúrgica das comunidades eclesiais.

Palavras-chave: Liturgia. Pandemia. Mistério de Cristo. Vida. Testemunho.

Abstract: This editorial reflects on the liturgical experience of ecclesial communities within the context of the COVID-19 pandemic that shook the world. The perspective that illuminates the reflections is that of an integral and dynamic vision of the Christian faith, which unites worship and life. The studies contained in the Liturgy Dossier of this Teocommunicação's issues are taken into account: a) Arnaldo Temochko's article on the Liturgy of the Hours as a possibility of prayer for families; b) the article written by Rudy Albino da Assunção on Benedict XVI's Theology of Liturgy; c) João José Bezerra's article that deals with Liturgy as a theological science and its relationship with other sciences; d) Michelle Girardi Lorenzetti's article that deals with the liturgical-musical formative processes in the Archdiocese of Porto Alegre. At the end, it reaffirms the need to bring the different realities present in the pandemic closer to the liturgical experience of ecclesial communities

Keywords: Liturgy. Pandemic. Mystery of Christ. Life. Testimony.

Resumen: Este editorial reflexiona sobre la experiencia litúrgica de las comunidades eclesiales en el contexto de la pandemia COVID-19 que sacudió al mundo. La perspectiva que ilumina las reflexiones es la de una visión integral y dinámica de la fe cristiana, que une culto y vida. Se tienen en cuenta los estudios contenidos en el Dossier de Liturgia de este número de Teocomunicação: a) El artículo de Arnaldo Temochko sobre la Liturgia de las Horas como posibilidad de oración para familias en los hogares; b) el artículo de Rudy Albino da Assunção sobre la Teología de la Liturgia de Benedicto XVI; c) el artículo de João José Bezerra que trata sobre la liturgia como ciencia teológica y su relación con otras ciencias; d) el artículo de Michelle Girardi Lorenzetti que trata sobre los procesos formativos litúrgico-musicales en la Arquidiócesis de Porto Alegre. Al final, se reafirma la necesidad de acercar las diferentes realidades presentes en la pandemia a la experiencia litúrgica de las comunidades eclesiales.

Palabras clave: Liturgia. Pandemia. Misterio de Cristo. Vida. Testimonio. 
Os artigos que compõem o Dossiê sobre Liturgia da revista Teocomunicação, em 2021, refletem sobre diferentes aspectos da renovação da vida litúrgica, na perspectiva do Concilio Vaticano II. A ocasião para essa reflexão é propícia, visto a comemoração próxima dos sessenta anos da Constituição Sacrosanctum Concilium, prevista para 2023. O trabalho de recepção litúrgica do Vaticano II continua se desenvolvendo, especialmente diante dos novos contextos socioculturais, como o da pandemia de COVID-19.

As enfermidades, as mortes e o distanciamento controlado entre as pessoas no tempo de pandemia, colocou à prova a vivência litúrgica das comunidades eclesiais. Os cristãos precisaram fomentar outras formas de oração e de ação litúrgica a partir da realidade familiar, fortalecendo a consciência de pertencerem a uma "Igreja doméstica". Multiplicaram-se os subsídios de orações para os lares e os encontros de espiritualidade familiar online ${ }^{2}$. A proposta de Arnaldo Temochko, em seu artigo "Liturgia em tempos de pandemia" vai ao encontro desse movimento de fortalecimento da Igreja doméstica. Ele trata a Liturgia das Horas como uma possibilidade de oração eclesial para as familias em tempos de pandemia e pós-pandemia. Para isso, recupera aspectos teológicos e pastorais desenvolvidos na Tradição cristã, a partir da ótica da Igreja como povo de Deus do Concilio Vaticano II. Vale destacar que o fortalecimento da Igreja doméstica está alinhado com a prioridade pastoral estipulada pela Conferência Nacional dos Bispos do Brasil para os próximos anos, que é a formação de pequenas comunidades eclesiais missionárias (CNBB, 2019).

Dentro de uma visão integral da fé cristã, é salutar reafirmar que as Igrejas domésticas não substituem os templos, como também os cultos realizados nos templos não suplantam o testemunho de vida dos cristãos na sociedade. Há uma unidade e reciprocidade entre essas diferentes esferas. Quando os templos foram fechados por razões sanitárias, os fiéis leigos sen- tiram-se forçados a experienciar a centralidade do culto eucarístico por uma via negativa, isto é, a da ausência sacramental de Cristo. E, paradoxalmente, eles foram chamados a expressar com maior vigor sua vivência da Eucaristia por meio do testemunho. Pense-se, por exemplo, nos médicos, enfermeiros e demais agentes de saúde que realizaram em seus trabalhos um culto espiritual a Deus pela doação de si mesmos no cuidado incansável aos doentes. Pense-se nos demais trabalhadores, pais e mães de familia, que também colocaram em risco as suas vidas para continuar os serviços básicos dos setores de alimentação e de transportes, ou, ainda, naqueles que se uniram para lutar contra a fome que crescia vertiginosamente nas periferias. Para os cristãos, todas essas ações estão em perfeita consonância com o sentido existencial do culto eucarístico: fazer de suas vidas uma oblação a Deus (Rm 12,1).

Rudy Albino de Assunção, em seu artigo "O fundamento está no sacramento, a forma está na Eucaristia", reforça a dimensão existencial da liturgia cristã ao analisar a teologia de Bento XVI. Para o papa emérito, o culto eucarístico é, na sua essência, autodoação divina que transforma a vida do fiel em missão (Sacramentum caritatis, $n$. 70-93). Assim, a vida cristã transforma-se em uma liturgia prolongada. Ele afirma: "o culto a Deus na existência humana não pode ser relegado para um momento particular e privado, mas tende, por sua natureza, a permear cada aspecto da realidade do individuo" (Sacramentum caritatis, n. 71). Alcança-se, desta maneira, uma visão mais dinâmica e integral da liturgia cristã.

O tempo de pandemia, apesar de bons exemplos, também colocou em evidência algumas compreensões redutivas sobre o culto eucarístico. De uma parte, houve grupos tradicionalistas que criticaram severamente o fechamento das Igrejas, mesmo no periodo mais crítico da pandemia. A compreensão estática da Eucaristia - dada na excessiva formalização do rito -, não lhes possibilitou a valorização da presença de Cristo nas 
dinâmicas históricas, manifestadas, neste caso, no sofrimento das vítimas de COVID-19. É certo, na fé cristã, que o Cristo se faz presente sobretudo nas espécies eucarísticas, mas, na impossibilidade de recebê-lo sacramentalmente, o Senhor clamou nos doentes e sofredores (Mt 25,31-45). O cuidado pelas vidas compõe o mandamento novo de Jesus Cristo (Jo 13.34) e expressa a vontade de Deus de conceder a vida em abundância para o seu povo (Jo 10,10). A afirmação de Santo Irineu torna-se, aqui, emblemática: "a glória de Deus é o homem vivo" (Contra as Heresias, IV, 20,7).

De outra parte, o tempo da pandemia também possibilitou a manifestação de uma compreensão racionalista do culto, "indiferente à forma litúrgica" e que corre o risco de pensar o rito como um evento do passado. Nesse caso, a ação sacra é "quase colocada de lado, calada, sendo um simples suporte contingente de uma ideia teológica" (GRILLO, 2017, p. 29). Esse modo de pensar conduziu alguns a uma relativização do culto e da reabertura das Igrejas quando o poder público já permitia o gradativo retorno da população aos espaços públicos das cidades.

As considerações sobre a vida litúrgica em tempos de pandemia fazem notar o quão importante é uma correta e equilibrada compreensão da relação entre liturgia e vida. Nesse sentido, o artigo de João José Bezerra, intitulado "Descoberta da Liturgia como ciência teológica e sua relação com as ciências humanas", ilumina essa relação. O autor explicita, citando Andrea Grillo, a importância das ciências humanas, como a Antropologia, a Psicologia e a Sociologia, para a estipulação de um frutuoso diálogo entre a celebração do mistério de Cristo e as diferentes realidades vivenciais dos fiéis (GRILLO, 2011). Os frutos desse diálogo podem ser aplicados no contexto pandêmico, entre outras maneiras, por meio de uma melhor abordagem do luto dos familiares das vítimas de COVID-19 nas celebrações litúrgicas.

A música litúrgica, por sua vez, é um lugar privilegiado na liturgia para expressar a relação entre o mistério de Cristo e as realidades de alegria, de dor, de angústia e de esperança do povo cristão. A proposta de Michelle Girardi Lorenzetti, em seu artigo sobre os processos formativos litúrgico-musicais na Arquidiocese de Porto Alegre, é reveladora desse diálogo entre a realidade local, marcada pela pandemia, e o culto. Ela analisa o processo de composição do Hinário litúrgico dessa Arquidiocese, realizado por meio da escuta de diferentes agentes de pastoral envolvidos na animação litúrgico-musical durante os anos de 2019 e 2021. A possibilidade de participação dos fiéis, respeitando a história da Igreja de Porto Alegre, mostra a preocupação de tornar a dinâmica ritual mais próxima da realidade cultural das pessoas.

Enfim, o presente editorial pretendeu, enquanto expressão da intenção dos editores da Teocomunicação, aproximar as diferentes realidades presentes na pandemia com a vivência litúrgica das comunidades eclesiais. Afinal, o verdadeiro culto a Deus, em espírito e em verdade, sempre contém e expressa a realidade vivencial dos fiéis.

\section{Referências}

CONFERENNCIA NACIONAL DOS BISPOS DO BRASIL. Diretrizes Gerais da Ação Evangelizadora da Igreja no Brasil 2019-2023. Brasilia: CNBB, 2019.

CONFERÊNCIA NACIONAL DOS BISPOS DO BRASIL. Roteiros celebrar em familia. In: CNBB. [S. I.], 2021. Disponivel em: https://www.cnbb.org.br/celebrar-familia. Acesso em: 20 nov. 2021

CONCÍLIO ECUMÊNICO VATICANO II, 1962-1965, Cidade do Vaticano. Sacrosanctum Concilium. In: COSTA, Lourenço (org.). Documentos do Concilio Vaticano II. 4. ed. São Paulo: Paulus, 2007. p. 33-86.

GRILLO, Andrea. Introduzione alla teologia liturgica: aproccio teórico alla liturgia e ai sacramenti cristiani. Padova: Messagero di Sant' Antonio, 2011.

GRILLO, Andrea. Ritos que educam: os sete sacramentos. Brasilia: Edições CNBB, 2017.

IRINEU DE LIÃO. Contra as heresias: denúncia e refutação da falsa gnose. Tradução de Lourenço Costa. São Paulo: Paulus, 1995. (Coleção Patrística).

PAPA BENTO XVI. Exortação Apostólica Pós-Sinodal Sacramentum Caritatis. In: Vatican. Vaticano, 22 fev. 2007. Disponivel em: https://www.vatican.va/content/ benedict-xvi/pt/apost_exhortations/documents/ hf_ben-xvi_exh_20070222_sacramentum-caritatis.html. Acesso em: 20 nov. 2021. 


\section{Rafael Martins Fernandes}

Doutor em Teologia Sistemática pela Pontifícia Universidade Lateranense, em Roma, Itália; bolsista do Programa Nacional de Pós-doutoramento (Capes); professor colaborador no Programa de Pós-Graduação em Teologia da Pontifícia Universidade Católica do Rio Grande do Sul (PUCRS), em Porto Alegre, RS, Brasil.

\section{Carlos Gustavo Haas}

Mestre em Liturgia pelo Pontificio Istituto Liturgico, em Roma, Itália. Professor e coordenador do Curso de Teologia da Pontifícia Universidade Católica do Rio Grande do Sul (PUCRS), em Porto Alegre, RS, Brasil. Membro da Comissão da Doutrina da Fé na Conferência Nacional dos Bispos do Brasil, em Brasilia, Brasil. Perito da Comissão de Liturgia no Conselho Episcopal Latino-americano, em Bogotá, Colômbia.

\section{Endereço para correspondência}

\section{Rafael Martins Fernandes/Carlos Gustavo Haas}

Pontificia Universidade Católica do Rio Grande do Sul

Escola de Humanidades - Curso de Graduação em Teologia

Av. Ipiranga, 6681, Prédio 8

Partenon, 90619900

Porto Alegre, RS, Brasil

Os textos deste artigo foram revisados pela Poá Comunicação e submetidos para validação do(s) autor(es) antes da publicação. 